\title{
STUDI PEMBUATAN BESI COR MAMPU TEMPA UNTUK PRODUK SAMBUNGAN PIPA
}

\author{
Agus Yulianto \\ Jurusan Teknik Mesin Fakultas Teknik UMS \\ Jl. A. Yani Pabelan - Kartosuro, Tromol Pos 1 Telp. (0271) 715448 Surakarta
}

\begin{abstract}
ABSTRAK
Tujuan penelitian ini adalah mengetahui proses pembuatan sambungan pipa(pipe fitting) dari besi cor putih dilakukan untuk dapat mengetahui kualitas dengan cara melakukan pengujian material setelah melalui proses heat treatment dengan cara proses annealing di antaranya pengujian : struktur mikro, kekerasan dan tarik. Dari produk pengecoran tersebut akan dibagi menjadi dua spesimen benda uji, yaitu satu (sambungan pipa) untuk proses annealing laboratorium dengan uji struktur mikro, uji kekerasan serta uji tarik dan satu (coran poros) untuk proses annealing pabrik dengan uji tarik. Dari pengujian pengujian struktur mikro terdapat fasa perlit dan sementit. Pengujian kekerasan diperoleh harga kekerasan rata-rata untuk daerah tengah $325 \mathrm{~kg} / \mathrm{mm}^{2}$ dan daerah gigi $351 \mathrm{~kg} / \mathrm{mm}^{2}$. Dari hasil uji tarik diperoleh harga rata-rata kekuatan tarik untuk spesimen annealing pabrik, yaitu $194,86 \mathrm{~N} / \mathrm{mm}^{2}$. Sedangkan spesimen annealing laboratorium harga rata-rata kekuatan tariknya adalah 158,85 $\mathrm{N} / \mathrm{mm}^{2}$.
\end{abstract}

Kata Kunci: annealing, struktur mikro, kekerasan, tarik.

\section{PENDAHULUAN}

Sambungan pipa (pipe fitting) banyak dijumpai dilingkungan kita sehari-hari baik itu di toko-toko material maupun di PDAM. Dan dengan berkembangnya teknologi dimana industri sudah semakin maju dan persaingan produk yang semakin meningkat maka konsumen dihadapkan pada beberapa jenis pilihan khususnya pada sambungan pipa (pipe fitting).

Dari berbagai macam produk dan bentuk sambungan pipa besi cor, masyarakat pada umumnya banyak menggunakan produk-produk tertentu yang dipasarkan di daerah tersebut tanpa mengetahui kualitas dari sambungan pipa. Untuk mendapatkan kualitas yang lebih baik maka material dari sambungan pipa perlu dilakukan proses perlakuan panas (proses heat treatment). Dimana proses ini merupakan kombinasi proses pemanasan dan pendinginan pada laju tertentu untuk mendapatkan sifat-sifat besi yang diingin- kan pada batas kemampuan dari besi cor tersebut.

Proses heat treatment yang akan dilakukan pada sambungan pipa (pipe fitting) besi cor yakni dengan cara annealing yang berfungsi untuk mengurangi kekerasan, menghilangkan tegangan sisa, dan mengurangi adanya segregasi (pemisahan). Untuk itu kami mencoba meneliti dan menganalisa suatu material agar dapat diketahui serta unsur-unsuryang terkandung pada material tersebut.

\section{BATASAN MASALAH}

Untuk menjelaskan ruang lingkup dari permasalahan dan mempermudah analisa masalah dalam makalah ini, maka perlu diberi batasanbatasan sebagai berikut :

\section{Material}

Material yang akan digunakan adalah sambungan pipa (pipe fitting) besi cor putih setelah perlakuan panas. 
2. Pengujian yang dilakukan
a. Perlakuan panas annealing
b. Pengujian struktur mikro
c. Pengujian kekerasan
d. Pengujian tarik

\section{TUJUAN PENELITIAN}

Manfaat yang dapat diambil dari penelitian kualitas sambungan pipa (pipe fitting) besi cor putih ini nantinya diharapkan bagi konsumen atau pengguna dapat mengetahui kualitas sambungan pipa (pipe fitting) besi cor berdasarkan dari analisa struktur mikro, harga kekerasan, dan kekuatan tariknya.

\section{LANDASAN TEORI}

Tri Murtopo (2002) meneliti tentang "Pengaruh Proses Perlakuan Panas Pada Baja Tahan Karat Produksi Pengecoran Logam di Klaten". Dari hasil uji struktur mikro mempunyai struktur feritnya lebih banyak dan mempunyai ukuran butiryang lebih besar maka benda ituakan mempunyai harga kekerasan yang kecil. Sedangkan berdasarkan uji tarik, benda yang telah mengalami perlakuan panas dan pendinginan baik pendinginan diudarabebas maupun pendinginan didalam oven dengan cerobong terbuka atau pendinginan didalam oven dengan cerobong tertutup, mempunyai kekuatan tarik yang menurun bila dibandingkan dengan benda sebelum mengalami panas. Hal ini disebabkan karena lambatnya laju pendinginan yang terjadi, sehingga akan menimbulkan butiran yang terbentuk menjadi besar. Butiran yang besariniakan membuatkekuatan baja menjadi rendah sehingga baja mudah putus.

Waspodo Martojo dan Ahmad T. Joenoes (2000) meneliti tentang "Peningkatan Kekuatan Mekanik dari Besi Cor Nodular Melalui Paduan dan Proses Perlakuan Panas Austempering" bahwa proses perlakuan panas dilakukan dengan memanaskan material sampai suhu austenisasinya kemudian didinginkan dengan cara kejut pada suhu di atas temperatur standar pada larutan garam pada suhu sekitar $250^{\circ} \mathrm{C}$ sampai $450{ }^{\circ} \mathrm{C}$. Hasil penelitian menunjukkan bahwa pengaruh perlakuan panas menyebabkan fasa austenit tidak sempat bertransformasi menjadi fasa ferit atau perlit, tetapi berubah menjadi bainit atau accicular ferrit.

Agus Joko Santoso (2003) meneliti tentang "Pengaruh Proses Annealing Terhadap Perubahan Struktur Mikro dan Kekerasan Sprocket Toyota Kijang" pada proses ini nampak adanya fasa ferit dan perlit, sehingga dihasilkan struktur butir ferit dan perlityang lebih besaryang dapat mempengaruhi harga kekerasannya terutama pada ferit yang mempengaruhi kelunakan pada sprocket tersebut, hal ini disebabkan adanya unsur $\mathrm{C}$ yang berdifusi kebatas butir.

\section{Besi Cor}

Besi cor (castiron) adalah campuran antara besi dan karbon yang berisi beberapa unsur lain seperti Si, Mn, S, dan P kandungan karbon tinggi sehingga besi cor bersifat rapuh dan tidak dapat ditempa. Besicormempunyai sifat fisis ataumekanis yang berbeda-beda, hal ini dipengaruhi oleh unsur paduan yang terkandung di dalamnya. Kandungan karbon dalam besi cor antara $2 \%-6,6 \%$ tetapi yang dibuat dalam perdagangan antara $2,5 \%-4 \%$.

Jenis-jenis utama dari besi tuang dapat kita bagi ke dalam :

1. Besi tuang kelabu (besi cor)

2. Besi tuang putih

3. Besi tuang yang dapat ditempa

4. Besi tuang nodular

Besi tuang kelabu atau besi cor (FC) adalah jenis material yang sering digunakan oleh manusia untuk menunjang kehidupannya. Besi cor adalah besi ( $\mathrm{Fe}$ ) yang mengandung unsur pospor. Keunggulanbesicoradalah proses pembuatanyangmudah dan murah serta penggunaan peralatannya cukup sederhana. Untuk memperoleh besi tuang kelabu sebagai dasarnya digunakan besi kasarkelabu. Besi kasar kelabu mempunyai kadar silisium tinggi $(0,5$ hingga 1,5\%) dankadarmangan yang rendah. Oleh karenaitu pembentukan zat arang bebas meningkat. Besituangkelabu setelah pendinginan mengandung grafit, grafitmuncul sebagai pelat-pelat tipis dalam besi tuang. Pelat-pelat tipis inilah yang kita sebut dengan lamel. Dan lamel inilah yang sifatnya getas (mudah retak atau pecah) jika kena pukulan impak (pukulan tiba-tiba) maupun beban lentur, akibat dari grafit atau lamel. 


\section{Besi Cor Putih}

Besi cor putih banyak digunakan untuk pembuatan suku cadang yang tahan gesekan karena jumlah karbida yang besar 30\% (volume) tahan terhadap kikisan. Grafit berbentuk gumpalan dalam logam padat. Grafit ini tidak memiliki tepi-tepi yang tajam seperti serpih grafit. Memiliki keuletan tertentu dan lebih mampu tempa.

\section{Besi Cor Mampu Tempa}

Dibuat dari besi cor putih yang dimasukkan ke dalam tanur dalam waktu yang lama. Struktur sementit dari besi cor putih berubah menjadi ferit atau perlit dari karbon yang tertemper mengendap. Besi cor macam ini sangat baik keuletannya dan perpanjangannya dibandingkan dengan besi cor kelabu, lagi pula tidak cocok untuk coran yang tipis dan kecil karena sebelum proses perlunakan keuletannya rendah.

\section{METODOLOGI PENELITIAN}

\section{A. Diagram Alir Penelitian}

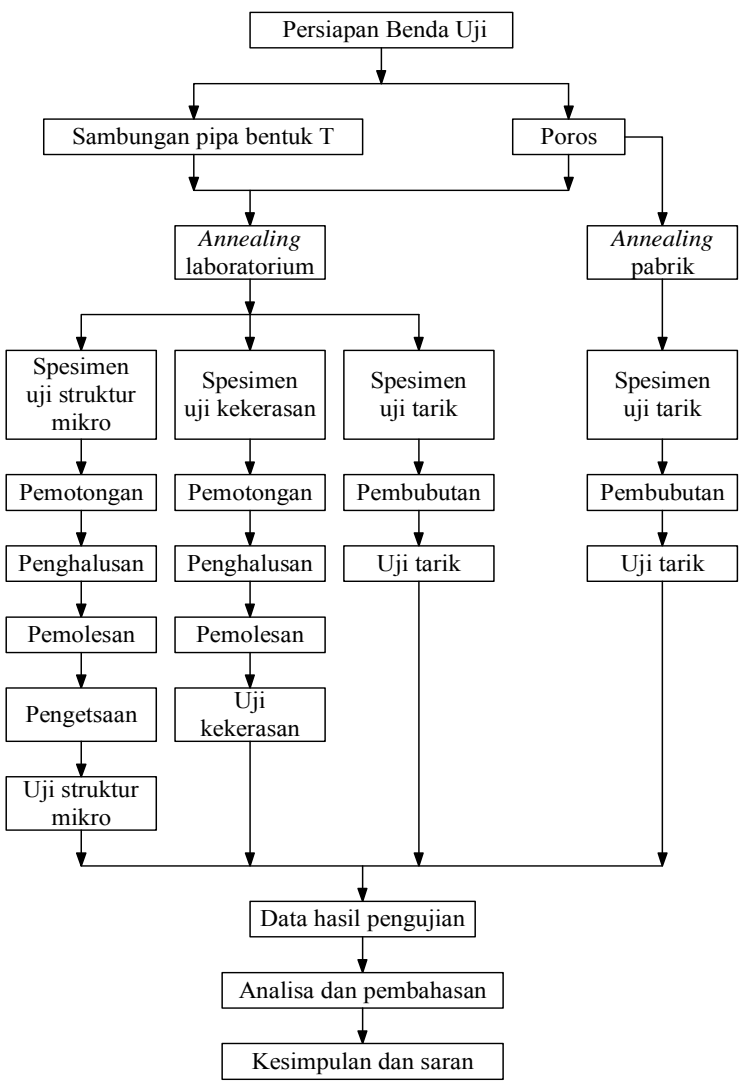

Gambar 1. Diagram Alir Penelitian

\section{B. Persiapan Benda Uji}

Besi cor merupakan material yang sangat keras, oleh karena itu dalam proses pemotongannya dilakukan dengan cara dipukul dengan menggunakan palu. Setelah material ini pecah kemudian diambil yang kecil untuk dilakukan pengujian struktur mikro dan kekerasan.

Agar dapat mempermudah dalam proses pengujian maka material tersebut di mounting terlebih dahulu. Adapun maksud dari mounting ini adalah supaya benda uji dapat diletakkan pada mesin uji dengan benar tanpa adanya pergeseran yang mengakibatkan kesalahan dalam pengujian.

\section{Penghalusan Permukaan dan Pemolesan}

Spesimen yang sudah di mounting kemudian dilakukan penghalusan pada permukaannya dengan menggunakan ampelas yang paling kasar sampai pada yang halus dengan nomor 120, 180, 400, 600, 1000.

Selama proses pengampelasan dilakukan pendinginan dengan menggunakan air secara terus menerus agar tidak menimbulkan panas dan permukaan benda uji lebih rata dan halus.

Proses pemolesan ini bertujuan untuk menghilangkan bekas pemakanan akibat proses pengampelasan. Pemolesan dilakukan berulang-ulang untuk mendapatkan permukaan yang halus dan mengkilat sampai tak ada goresan sehingga struktur benda uji semakin jelas dibawah mikroskop.

\section{Pengetsaan}

Proses pengetsaan dilakukan hanya pada benda uji yang akan dilihat struktur mikronya. Bahan etsa yang akan digunakan pada penelitian ini adalah nitrid acid $\left(\mathrm{HNO}_{3}\right)$ dan $15 \mathrm{ml}$ air selama \pm 1 menit. Kemudian dipanaskan dengan menggunakan hair dryer. Maksud dari pengetsaan ini adalah untuk menghilangkan lapisan yang menutupi permukaan akibat proses sebelumnya sehingga dapat dilakukan pemotretan dibawah mikroskop dan struktur mikronya dapat terlihat dengan jelas.

\section{Proses Annealing}

Annealing merupakan proses pemanasan suatu bahan dengan jalan memanaskan bahan sampai temperatur didaerah austenit, dibiarkan 
beberapa saat tergantung dari besar kecilnya bahan. Kemudian didinginkan didalam dapur itu sendiri dengan menghentikan pemberian panas sesuai dengan suhu kamar $\pm 27^{\circ} \mathrm{C}$. Proses annealing yang dilakukan adalah sebagai berikut:

\section{Annealing Pabrik}

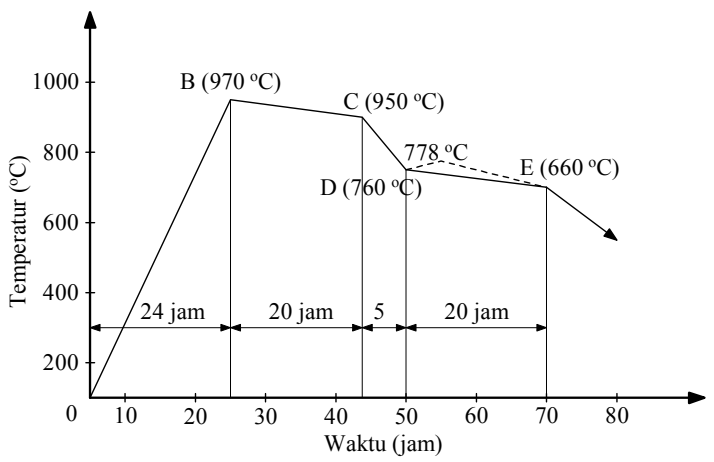

Gambar 2. Siklus Annealing Pabrik CV. ATMAJAJAYA

Keterangan:

A : Penyalaan I, kompor yang di nyalakan 4 buah dan api diusahakan menjadi gas.

$\mathrm{A} \rightarrow \mathrm{B} \quad$ : Suhu api tinggi $970{ }^{\circ} \mathrm{C}$, waktu yang diperlukan \pm 24 jam dan diusahakan gas api lebih cepat.

$\mathrm{B} \rightarrow \mathrm{C} \quad:$ Selama \pm 20 jam suhu api dipertahankan dengan penurunan suhu $\pm 1{ }^{\circ} \mathrm{C}$ sampai $2^{\circ} \mathrm{C}$ tiap jam hingga mencapai $950^{\circ} \mathrm{C}$.

$\mathrm{C} \rightarrow \mathrm{D}$ : Sesudah mencapai $950^{\circ} \mathrm{C}, 4$ (empat) kompor dimatikan selama \pm 5 jam hingga suhu mencapai $760^{\circ} \mathrm{C}$.

$\mathrm{D} \rightarrow \mathrm{E} \quad:$ Setelah mencapai $760^{\circ} \mathrm{C}$ dilakukan penyalaan II dengan menggunakan 2 (dua) kompor, suhu api dinaikkan $778^{\circ} \mathrm{C}$ setelah itu diturunkan lagi \pm 5 ${ }^{\circ} \mathrm{C}$ sampai $6{ }^{\circ} \mathrm{C}$ dalam tiap jam hingga mencapai $660^{\circ} \mathrm{C}$ selama 20 jam.

E : Pada saat suhu sudah mencapai $660^{\circ}$ C, 2 (dua) kompor dimatikan.

\section{Annealing Laboratorium}

Dalam proses annealing ini material dimasukkan kedalam dapur dengan suhu kamar mencapai $32{ }^{\circ} \mathrm{C}$, setelah $\pm 1,5$ jam suhu mencapai $950{ }^{\circ} \mathrm{C}$. Pada saat suhu mencapai 950 ${ }^{\circ} \mathrm{C}$ ditahan selama 2 jam setelah itu dapur dimatikan selama 24 jam kemudian material diambil dengan suhu mencapai $180^{\circ} \mathrm{C}$.

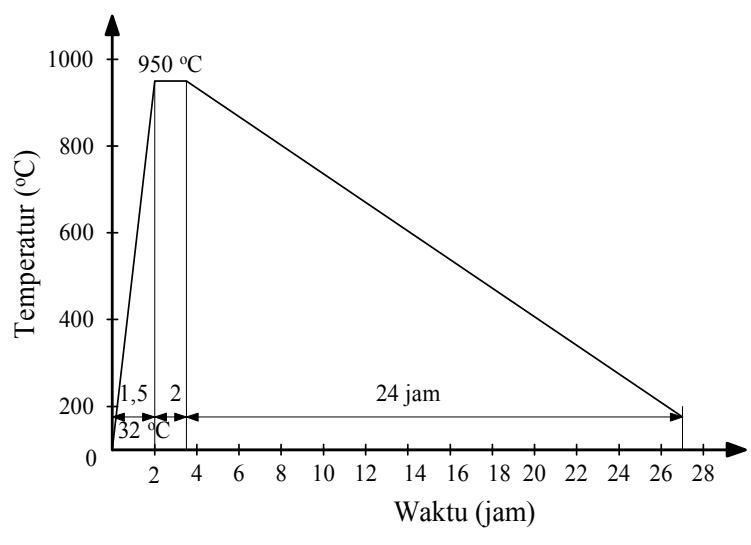

Gambar 3. Siklus Annealing Laboratorium D3 UGM

\section{Pengujian Tarik}

Kekuatan tarik (ultimate tensile strength) merupakan salah satu sifat penting suatu bahan. Uji tarik dapat dipakai untuk mengetahui bahan liat atau tidak dengan cara mengukur perpanjangannnya. universal.

Penelitian ini menggunakan mesin uji tarik

\section{E. Pengujian Struktur Mikro}

Pada pengujian metalografi ini bertujuan untuk mengamati struktur mikro dari material besi cor sambungan pipa (pipe fitting) setelah melalui proses annealing. Struktur ini akan terlihat jelas apabila permukaan spesimen benar-benar rata, halus, mengkilap tanpa ada goresan dan mengalami proses pengetsaan terlebih dahulu. Kemudian dicari fokus yang sesuai lalu dipotret dengan Microscope Olympus Photomicrographic System.

\section{F. Pengujian kekerasan}

Dalam penelitian ini pengujian kekerasan dilakukan dengan menggunakan uji kekerasan Brinell. Pengujian ini didasari pada kemampuan permukaan untuk menerima beban penetrator dari mesin uji kekerasan. 
Alat yang digunakan adalah Brinell Hardness Tester. Dipilihnya alat ini karena sangat cocok untuk material besi cor, disamping itu juga mudah dalam pengoperasiannya dan hasil kekerasannya secara langsung dapat dibaca.

Pada metode ini penetrator yang digunakan berupa bola baja berdiameter 2,5 mm sebagai penekan. Beban yang digunakan dalam penelitian ini sebesar $187,5 \mathrm{~kg} / \mathrm{mm}^{2}$ dengan lama pembebanan 15 detik.

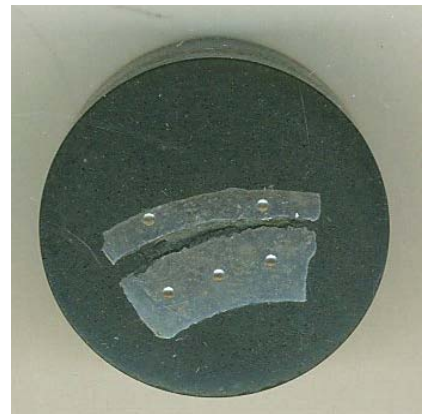

Gambar 4. Lokasi Titik Spesimen Uji Kekerasan

\section{DATA DAN HASIL PENELITIAN}

1. Data dan Hasil Pengujian Struktur Mikro Perlit

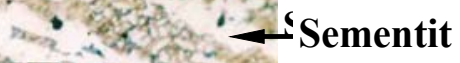

T untuk Daerah Gigi Pembesaran 200 x

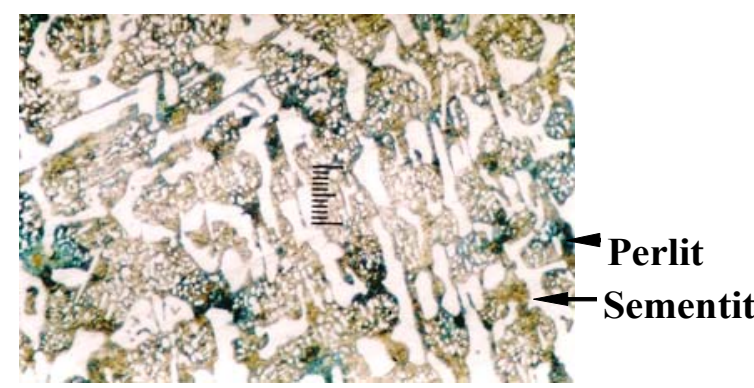

Gambar 6. Struktur Mikro Sambungan Pipa T untuk Daerah Gigi Pembesaran 500 x

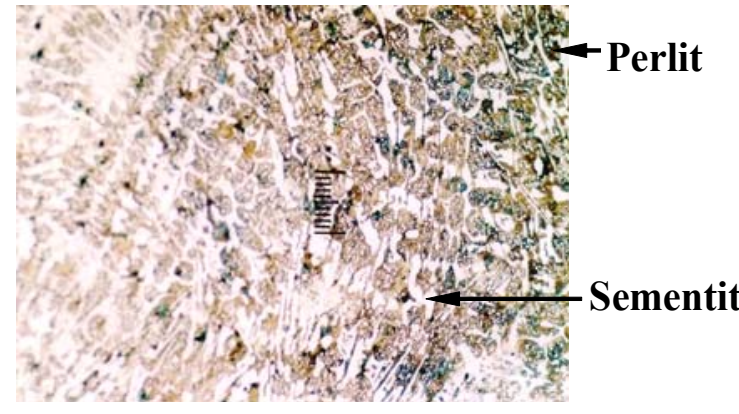

Gambar 7. Sruktur Mikro Sambungan Pipa T untuk Daerah Tengah Pembesaran 200x

Gambar 8. Struktur Mikro Sambungan Pipa T untuk Daerah Tengah Pembesaran 500x

\section{Data dan hasil pengujian kekerasan}

Tabel 1. Hasil Pengujian Kekerasan Sambungan Pipa T untuk Daerah Tengah

\begin{tabular}{|c|c|c|c|c|} 
No. & $\begin{array}{c}\text { Jarak } \\
\text { dari tepi } \\
(\mathbf{m m})\end{array}$ & $\begin{array}{c}\mathbf{D} \\
(\mathbf{m m})\end{array}$ & $\begin{array}{c}\text { Harga } \\
\text { kekerasan } \\
(\mathbf{H B N}) \\
\mathbf{k g} / \mathbf{m m}^{2}\end{array}$ & $\begin{array}{c}\text { Harga } \\
\text { kekerasan } \\
\text { rata-rata } \\
\left(\mathbf{k g} / \mathbf{m m}^{\mathbf{2}}\right)\end{array}$ \\
\hline 1 & acak & 0,84 & 329 & \multirow{2}{*}{325} \\
\cline { 1 - 3 } 2 & acak & 0,85 & 321 & \\
\hline
\end{tabular}

Tabel 2. Hasil Pengujian Kekerasan Sambungan Pipa T untuk Daerah Gigi

\begin{tabular}{|c|c|c|c|c|}
\hline No. & $\begin{array}{c}\text { Jarak } \\
\text { dari tepi } \\
(\mathrm{mm})\end{array}$ & $\begin{array}{c}\text { D } \\
(\mathrm{mm})\end{array}$ & $\begin{array}{c}\text { Harga } \\
\text { kekerasan } \\
(H B N) \\
\text { kg/mm }{ }^{2} \\
\end{array}$ & $\begin{array}{c}\text { Harga } \\
\text { kekerasan } \\
\text { rata-rata } \\
\left(\mathrm{kg} / \mathrm{mm}^{2}\right) \\
\end{array}$ \\
\hline 1 & acak & 0,82 & 345 & \multirow{3}{*}{351} \\
\hline 2 & acak & 0,81 & 354 & \\
\hline 3 & acak & 0,81 & 354 & \\
\hline
\end{tabular}




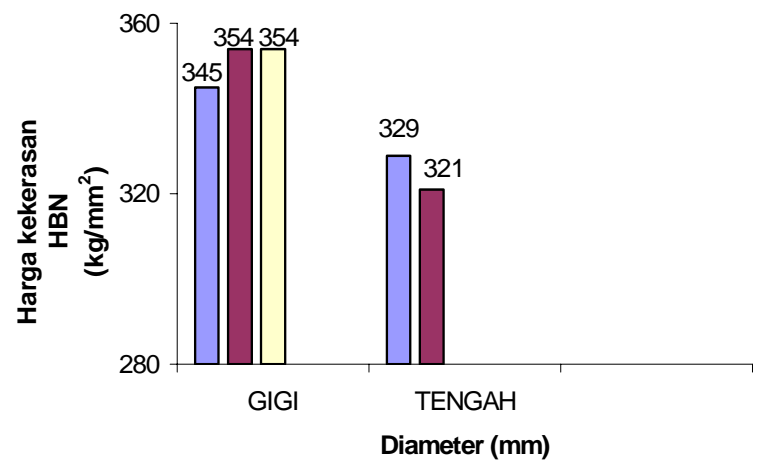

Gambar 9. Histogram Harga Kekerasan Sambungan Pipa T

\section{Data dan hasil pengujian tarik}

Tabel 3. Harga Kekuatan Tarik Annealing Pabrik

\begin{tabular}{|c|c|c|c|c|}
\hline No. & $\begin{array}{c}\text { Beban } \\
\mathbf{F} \\
\mathbf{( N )}\end{array}$ & $\begin{array}{c}\text { Luas } \\
\text { Penampang } \\
\mathbf{A o} \\
\left(\mathbf{m m}^{\mathbf{2}}\right)\end{array}$ & $\begin{array}{c}\text { Tegangan } \\
\text { Tarik } \\
\mathbf{\sigma t} \\
\left(\mathbf{N} / \mathbf{m m}^{2}\right)\end{array}$ & $\begin{array}{c}\text { Regangan } \\
\mathbf{\boldsymbol { ~ }} \\
\mathbf{( \% )}\end{array}$ \\
\hline 1. & 20450 & 63,585 & 321,617 & 14,68 \\
\hline 2. & 4330 & 63,585 & 68,098 & 4,34 \\
\hline
\end{tabular}

Tabel 4. Harga Kekuatan Tarik Annealing Laboratorium

\begin{tabular}{|c|c|c|c|c|}
\hline No. & $\begin{array}{c}\text { Beban } \\
\mathbf{F} \\
\mathbf{( N )}\end{array}$ & $\begin{array}{c}\text { Luas } \\
\text { Penampang } \\
\mathbf{A o} \\
\left(\mathbf{m m}^{\mathbf{2}}\right)\end{array}$ & $\begin{array}{c}\text { Tegangan } \\
\text { Tarik } \\
\mathbf{\sigma t} \\
\left(\mathbf{N} / \mathbf{m m}^{\mathbf{2}}\right)\end{array}$ & $\begin{array}{c}\text { Regangan } \\
\mathbf{\boldsymbol { \varepsilon }} \\
\mathbf{( \% )}\end{array}$ \\
\hline 1. & 8490 & 63,585 & 133,522 & 6,8 \\
\hline 2. & 11710 & 63,585 & 184,163 & 10,3 \\
\hline
\end{tabular}

\section{PEMBAHASAN}

\section{Pengujian Struktur Mikro}

Hasil foto struktur mikro pada sampel uji terdapat struktur perlit dan sementit, dimana bagian tersebut yang mendominasi adalah sementit. Sifat sementit itu sendiri sangat keras dan getas, serta sifat perlit ulet dan baik sekali ketahanan ausnya.

\section{Pengujian Kekerasan}

Hasil pengujian kekerasan pada sampel uji yang dilakukan adalah sebanyak 5 titik yaitu
2 titik untuk daerah tengah dan 3 titik untuk daerah gigi. Hal ini dilakukan agar data lebih akurat dan teliti. Hasil pengujian kekerasan dengan metode Brinell pada besi cor putih untuk produk sambungan pipa setelah melalui proses annealing laboratorium diperoleh harga kekerasannya sebagai berikut:

a. Untuk daerah tengah harga kekerasan pada bagian titik 1 dengan HBN 329 dan titik 2 diperoleh HBN 321, sedangkan harga kekerasan rata-rata dari kedua titik yaitu HBN 325.

b. Untuk daerah gigi harga kekerasan pada bagian titik 1 dengan HBN 345, sedangkan titik 2 dan 3 sama yaitu HBN 354 dan untuk harga kekerasan ratarata dari ketiga titik yaitu HBN 351 .

\section{Pengujian Tarik}

Dari hasil pengujian tarik untuk Annealing Pabrik Spesimen I didapatkan nilai kekuatan tarik sebesar 321,617 N/mm². Sedangkan untuk Spesimen II sebesar 68,098 N/mm². Dari hasil pengujian tarik untuk Annealing Laboratorium Spesimen I didapatkan nilai kekuatan tarik sebesar 133,522 N/mm². Sedangkan untuk Spesimen II sebesar $184,163 \mathrm{~N} / \mathrm{mm}^{2}$.

\section{KESIMPULAN}

Berdasarkan hasil data penelitian dan analisa yang didapat maka dapat disimpulkan sebagai berikut :

1. Dari pengamatan pada hasil pemotretan struktur mikro dapat disimpulkan bahwa struktur mikronya terdiri dari perlit dan sementit.

2. Nilai rata-rata kekerasan menurut metode Brinell dari besi cor putih untuk produk sambungan pipa (pipe fitting) dalam bentuk T untuk daerah tengah sebesar $325 \mathrm{~kg} / \mathrm{mm}^{2}$, sedangkan untuk daerah gigi sebesar 351 $\mathrm{kg} / \mathrm{mm}^{2}$.

3. Sebelum melakukan pengujian tarik, spesimen uji tarik di annealing terlebih 
dahulu. Proses annealing yang dilakukan adalah annealing pabrik dan annealing laboratorium. Dari hasil pengujian tarik maka dapat diperoleh harga kekuatan tariknya.

a. Annealing pabrik Batang no. 1 diperoleh harga kekuatan tariknya sebesar 321,617 N/mm² sedang- kan untuk batang no. 2 harga kekuatan tariknya sebesar $68,098 \mathrm{~N} / \mathrm{mm}^{2}$.

b. Annealing laboratorium

Batang no. 1 diperoleh harga kekuatan tariknya sebesar 133,522 N/mm² untuk batang no. 2 harga kekuatan tariknya sebesar 184,163 N/mm².

\section{DAFTAR PUSTAKA}

Martojo, W ; T. Joenoes, A., 2000, Peningkatan Kekuatan Mekanik dari Besi Cor Nodular Melalui Paduan dan Proses Perlakuan Panas Austempering, ITB, Bandung

Santoso, A.J., 2003, Pengaruh Proses Annealing Terhadap Perubahan Struktur Mikro dan Kekerasan Sprocket Toyota Kijang, UMS, Surakarta

Supardi, E., 1999, Pengujian Logam, Cetakan ke-2, PT. Angkasa, Bandung

Surdia, T; Chijiwa, K., 2000, Teknik Pengecoran Logam, Cetakan ke-8, PT. Pradnya Paramita, Jakarta

Tri Murtopo, 2002 Pengaruh Proses Perlakuan Panas Pada Baja Tahan Karat Produksi Pengecoran Logam di Klaten, UMS, Surakarta

Van Vlack, L. H., 1992, Ilmu dan Teknologi Bahan, PT. Gelora Aksara Pratama, Jakarta 